\title{
Delayed Airway Extrusion of Type 1 Thyroplasty Gore-Tex Implant
}

\author{
J Morris ${ }^{1}$, DM Thomas ${ }^{2}$ \\ ST51 $^{1}$ Registrar, Consultant ${ }^{2}$, \\ Gloucestershire Royal Hospital
}

\section{Background}

In 2005, a 46-year-old lady suffered with a right-sided unilateral idiopathic vocal fold palsy that failed to recover. She underwent a Type 1 Thyroplasty in which a length of Gore-Tex ribbon is implanted via an external approach to medialise the paralysed vocal fold and so improve voice quality.

\section{Method}

After an initial excellent response to the procedure and voice therapy she was discharged from follow-up. In 2015 she developed dysphonia and flexible nasendoscopy demonstrated an anterior commissure polyp and granulation tissue. The edge of the implant was seen extruding into an otherwise stable airway. The patient declined CT scanning and open removal of the implant. The patient chose to proceed to examination under anaesthetic and the implant was removed endoscopically. The patient recovered uneventfully and has declined a further medialistion procedure.

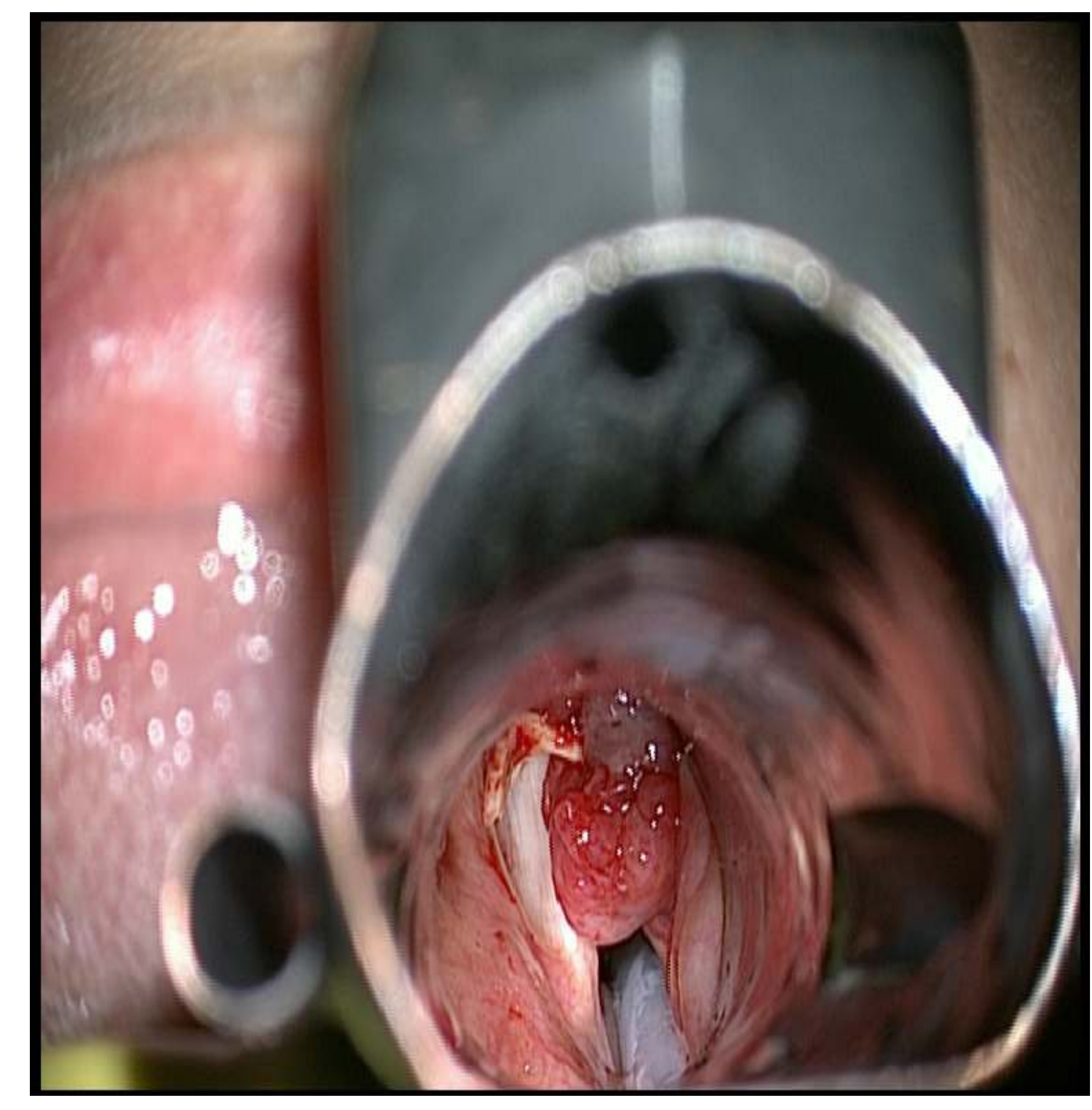

Figure 1 Implant extrusion into airway with associated granulation tissue.

\section{Results}

This was a popular technique for vocal cord medialisation. However the current favoured technique is injectable materials such as hyaluronic acid ${ }^{1}$.

Compilations such as rejection and extrusion of Gore-Tex implants following external approach thyroplasty have been reported at early stages but literature review did not reveal such a late manifestation ${ }^{2}$.

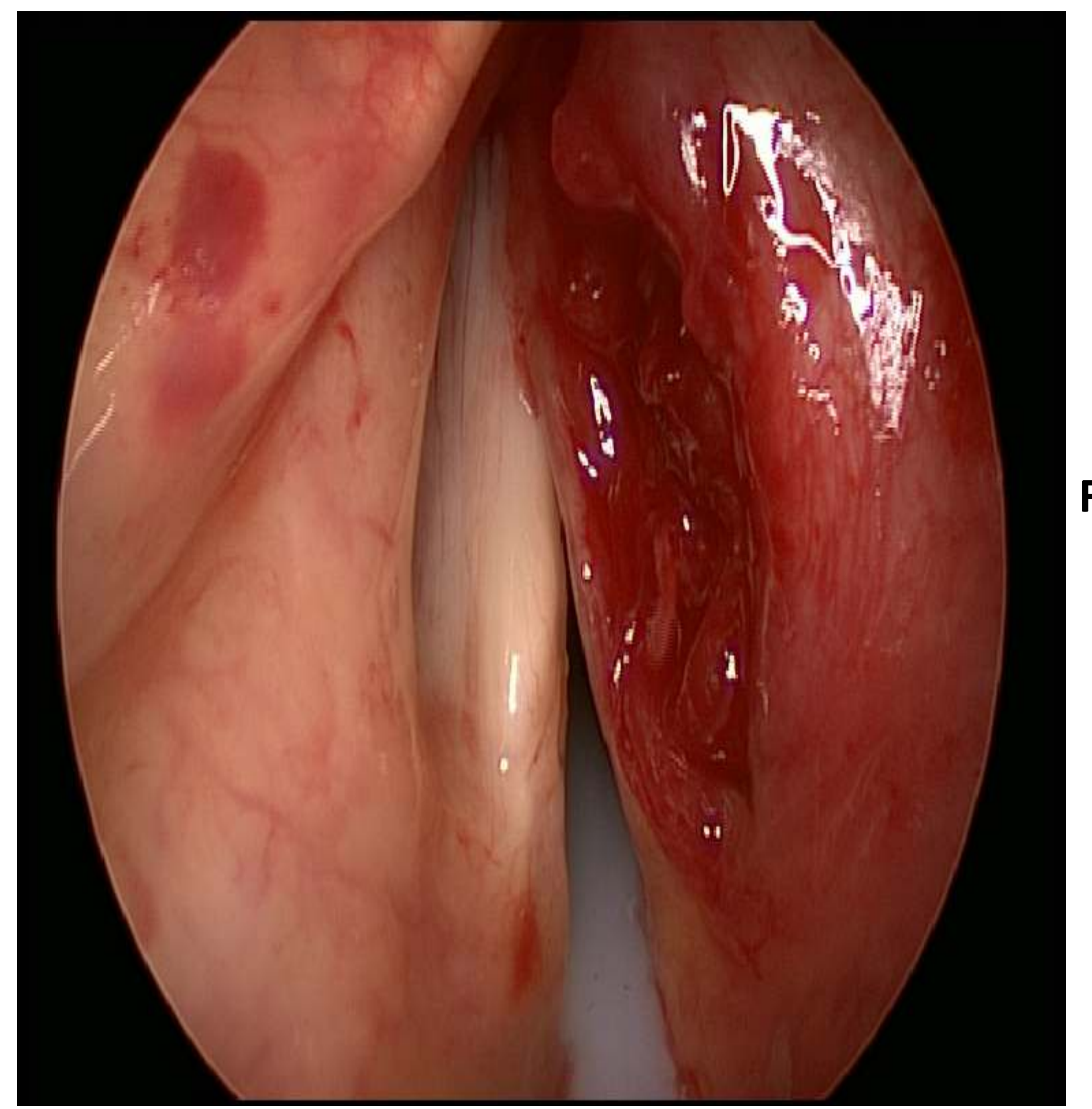

Figure 3 Post-extraction view.

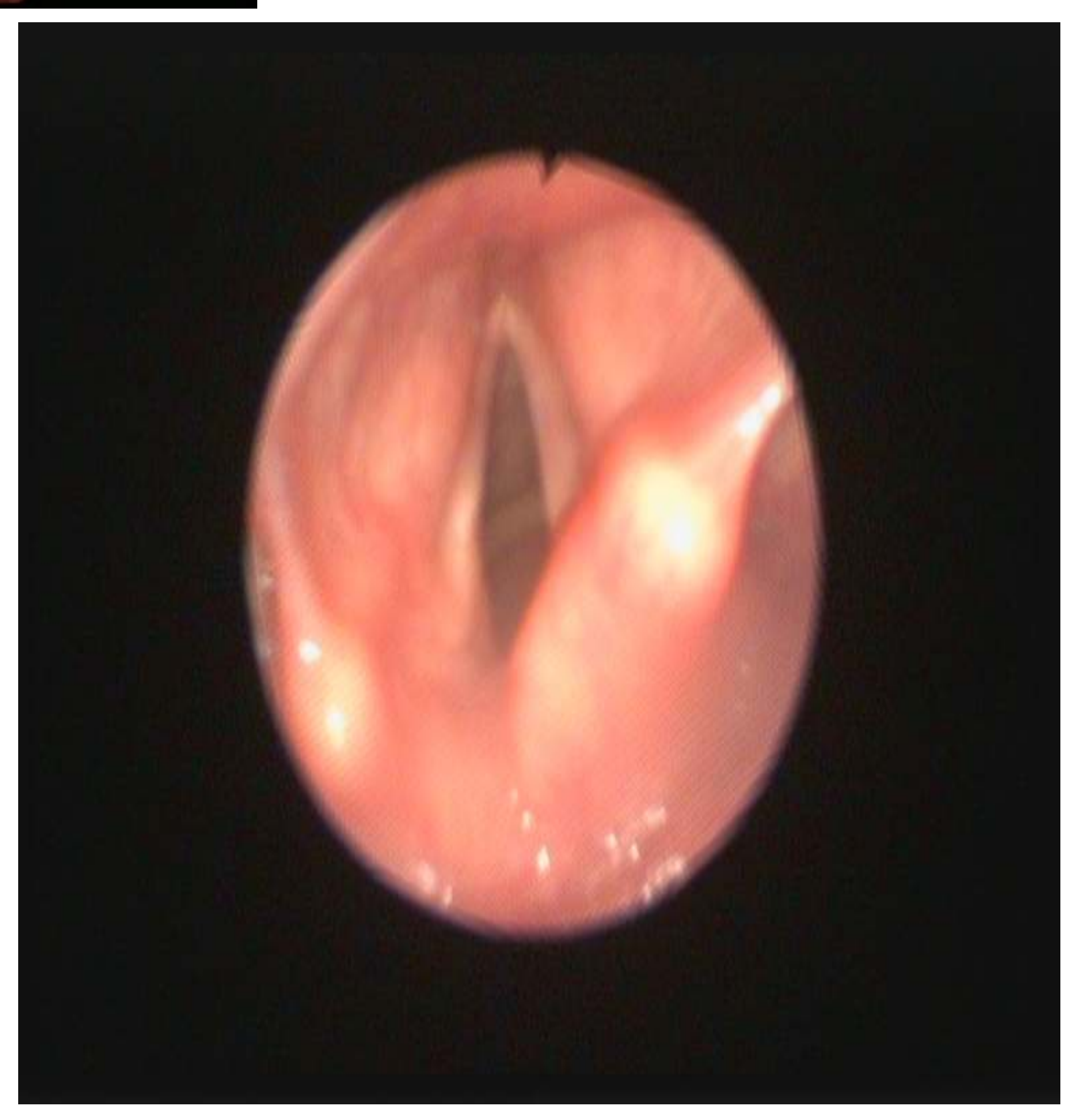

\section{Discussion/Conclusion}

This case is important because it highlights that extrusion of this material is possible at this late stage with potentially life-threatening consequences. 